\title{
Responsabilidad Internacional del Estado en la Protección de los Refugiados
}

\author{
Leticia Mirelli Faleiro e Silva \\ Máster en Protección de los Derechos Fundamentales por la Universidad de Itaúna. Abogada y Licenciada en Derecho por las \\ Facultades Integradas del Oeste de Minas. Postgraduada en Ciencias Criminales por la Universidad Gama Filho. Postgraduada en \\ Derecho del Trabajo y Procesal del Trabajo por la Facultad Pitágoras. faleiro.bueno.adv@hotmail.com \\ Rubén Miranda Gonçalves \\ Postdoctorando en Derecho en la Universidade do Estado do Rio de Janeiro; Doctor en Derecho por la Universidad de Santiago de \\ Compostela; Máster en Derecho de las Administraciones e Instituciones Públicas y Licenciado en Derecho por la Universidad de \\ Santiago de Compostela. ruben.miranda@usc.es
}

\section{RESUMEN}

Este artículo tiene por objeto abordar la resistencia de algunos Estados a recibir refugiados verificando si son signatarios del Estatuto de los Refugiados de 1951 y de su Protocolo de 67, y si cumplen con él. Se analizarán los decretos ejecutivos 13.769 y 13.780, de 2017, del presidente Donald J. Trump, para definir el objeto del estudio, suspendiendo el Programa de Admisión de Refugiados en los Estados Unidos. Además de estos documentos, también se examinará la Declaración firmada por la Unión Europea y Turquía el 16 de marzo de 2016, para restringir la entrada de personas con estatuto de refugiado en los países europeos. El aspecto metodológico adoptado para la realización de este artículo ha sido el jurídico-dogmático; tipo de razonamiento: deductivo; tipos metodológicos de investigación: histórico-jurídico, jurídico-interpretativo, jurídico-prospectivo y jurídico-positivo.

Palabras-clave: Admisión de refugiados. Acto ilícito internacional. Responsabilidad civil y penal.

\section{INTERNATIONAL RESPONSIBILITY OF THE STATE FOR THE PROTECTION OF REFUGEES}

\section{ABSTRACT}

This article intends to address the resistance of certain States to receive refugees, verifying whether they are parties to the 1951 Refugee Convention and its Protocol of 67, and if they comply with them. Delimiting the researched object, the President Donald J. Trump's Executive Orders 13.769 and 13.780, of 2017, are examined, which suspend the US Refugee Admissions Program. In addition to these documents, the Declaration signed by the European Union and Turkey on 16 March 2016 to restrict the entry of refugees into European countries is also the subject of the study. Subsequently, the arguments raised during the issuance of these restrictive documents will be investigated, with the objective to investigate the alleged practice of an international illicit, susceptible to liability and reparation for any damages caused. The methodological aspects adopted: juridical-dogmatic; reasoning type: deductive; research methodological types: juridical-historical, juridical-interpretative, juridical-prospective and juridical-propositional.

Keywords: Admission of refugees. International illicit act. Civil and criminal liability.

1 Introducción. 2 Panorama Global del Refugio. 2.1 Estatuto de los Refugiados de 1951 y su Protocolo de 1967. 2.2 Mecanismos adoptados por la Unión Europea y los Estados Unidos para evitar la entrada de los refugiados en sus territorios. 2.3 Mecanismos adoptados por la Unión Europea y Estados Unidos contra el Instituto Legal de la Responsabilidad Internacional del Estado. 3 Conclusión. 


\section{INTRODUCCIÓN}

Todas las personas nacen con el derecho a recibir el mismo trato, con la misma consideración y respeto, es decir, aunque todos los seres humanos estén dotados de ciertas características que los distinguen de otros seres, siguen siendo receptores naturales de la misma atención (APPIO, 2008, p. 195).

Después del final de la Segunda Guerra Mundial, la necesidad de proteger a las minorías se vio reforzada por la comprensión de que existe una propensión del ser humano a ejercer el papel de opresor (APPIO, 2008, p. 196).

En este sentido, es necesario conceptualizar el término minorías como ser:

[...] determinadas classes de pessoas que não têm acesso à mesma representação política que os demais cidadãos, ou, ainda, que sofrem histórica e crônica discriminação por conta de características essenciais a sua personalidade que demarcam a sua singularidade no meio social (APPIO, 2008, p. 200).

En vista de esta definición, se observa que los refugiados forman parte de una minoría fácilmente identificable y, por lo tanto, tienen más probabilidades de ser víctimas de discriminación en todas sus formas y de que se violen sus derechos. Sin embargo, es necesario reconocer su mayor vulnerabilidad y, en consecuencia, la necesidad de garantizarles una mayor protección, especialmente por parte de los Estados.

El Alto Comisionado de las Naciones Unidas para los Refugiados (Acnur) presentó su último informe titulado "Global Trends" (ACNUR, 2015), elaborado en 2015, que registra los desplazamientos forzados en todo el mundo a partir de datos proporcionados por los gobiernos, los organismos asociados y el propio Acnur.

A finales de 2015, 65,3 millones de personas habían sido desplazadas en el mundo debido a guerras y conflictos, de las cuales 21,3 millones son refugiados, 3,2 millones son solicitantes de asilo y 40,8 millones son desplazados internos que permanecen en sus propios países.

Entre los países analizados por Global Trends, algunos destacan por ser la principal fuente de refugiados en el mundo, a saber, Siria, que cuenta con 4,9 millones de refugiados, Afganistán, con 2,7 millones, y Somalia, con 1,1 millones, países que constituyen la mitad de los refugiados bajo el mandato de Acnur, y el país que más refugiados recibe es Turquía, que cuenta con 2,5 millones.

En este sentido, es pertinente abordar en este artículo uno de los principales problemas a los que se enfrentan los refugiados en la actualidad, en particular, los mecanismos creados por algunos Estados para impedir su entrada en sus territorios, mediante la adopción de una política de "cierre de fronteras", por así decirlo, con el fin de determinar finalmente si la postura adoptada por estos países es compatible con los compromisos que han asumido en la escena internacional.

Para una mejor explicación, es necesario traer el concepto primario de la palabra refugio, aunque sea de una manera sencilla, es decir, escondrijo, un lugar donde nos escondemos de los demás para no ser vistos o descubiertos. Refugio proviene del latín refugium, que significa un lugar para estar seguro, o literalmente, huir hacia atrás (FRANCO FILHO, 2013, p. 79). 
En este punto, es importante mencionar que el asilo y el refugio son institutos legales completamente diferentes, y sobre esta diferencia Mazzuoli afirma:

Por outro lado, enquanto o refúgio tem natureza claramente humanitária, o asilo tem natureza tipicamente política. Ademais, enquanto para a concessão do primeiro basta um fundado temor de perseguição, para a concessão do segundo necessário se faz uma perseguição concreta (ou seja), já materializada. Outra diferença está no fato de ser a concessão do asilo medida discricionária do Estado, ao passo que para concessão do refúgio há requisitos (de ordem internacional e interna) a serem observados, os quais estando completos, fazem com que a concessão do refúgio se efetive (MAZZUOLI, 2016, p. 828829).

Incluso antes de que el refugio fuera reconocido como un instituto jurídico propio, existía desde tiempos bíblicos, pues se relatan historias de personas que se vieron obligadas a abandonar su país a causa de la persecución, y por esta razón buscaron refugio en un lugar seguro. En este sentido, Andrade hace hincapié en que:

O homem convive, desde os mais remotos tempos, com o fato de ter de sair de sua plaga de origem em razão de ter desagradado seus governantes, ou a sociedade na qual vive. A infração cometida enseja, como punição por parte de quem detém o poder, seja suspensa a guarida ao faltoso que tem, conseqüentemente, de buscar alhures a proteção perdida (ANDRADE, 1996, p. 8).

En este mismo sentido, Pacífico añade que "La Biblia recuerda la historia de la Sagrada Familia (José, María y el niño Jesús) que se vio obligada a abandonar su casa y a refugiarse en Egipto para escapar de Herodes" (PACíFICO, 2010, p. 39).

A partir de ahí se entiende que el refugio acompaña a la humanidad desde el principio, aunque de forma discreta, ganando una mayor dimensión y nuevo formato a medida que la colectividad evoluciona lato sensu.

Este tema surge de manera significativa, asumiendo un nuevo vestuario, por así decirlo, a partir de la década de 1920, debido al final de la Primera Guerra Mundial, intensificándose con el surgimiento de la Segunda Guerra Mundial, con el consiguiente desplazamiento forzado masivo de personas en Europa.

Este intenso movimiento despertó en la comunidad internacional la preocupación por estas personas y, a partir de entonces, nació la necesidad de conceder protección jurídica a este grupo minoritario de individuos, llamados refugiados.

Sin embargo, desde la concesión inicial de la protección a los refugiados se han logrado numerosos y significativos avances, el refugio se presenta todavía como un problema de orden público y humanitario en el contexto mundial, regional e interno, que requiere una atención aún mayor.

Este artículo adoptará un enfoque más general del Estatuto de Refugiado, comenzando con su reconocimiento como instituto jurídico de protección, presentando su fase histórica, seguida por el escenario normativo global, con la aprobación de la Convención sobre el Estatuto de los Refugiados de 1951 y su Protocolo de 1967. 
A continuación se presentarán los mecanismos creados por los países de la Unión Europea y los Estados Unidos de América para impedir la entrada de refugiados en sus territorios, y se concluirá con un enfoque amplio del instituto jurídico de la Responsabilidad Internacional del Estado ante el cierre de fronteras por parte de estos Estados, para determinar si se ha cometido un acto internacional ilícito característico de la Responsabilidad Internacional del Estado, sujeto a indemnización, especialmente en lo que respecta a la protección de los refugiados.

La metodología utilizada será la investigación bibliográfica, a través de la consulta en doctrinas, textos y artículos científicos, así como la investigación documental sustentada en la lectura de leyes y sentencias relacionadas con la materia. También se utilizará la consulta de datos estadísticos de Acnur y de sitios web, mediante un análisis teórico, interpretativo e histórico. El método adoptado será deductivo.

\section{PANORAMA GLOBAL DEL REFUGIO}

En primer lugar, es importante señalar que, a través de los estudios desarrollados hasta ahora, se encontró que el refugio ya existía incluso antes de su reconocimiento normativo. En este sentido:

Pode- se afirmar que a proteção dos refugiados, de forma coordenada, iniciou-se por meio das atividades da Liga das Nações. Isso se deu, primordialmente, em razão de acontecimentos que tiveram lugar pouco antes, durante e, em especial imediatamente após a primeira grande guerra (ANDRADE, 1996, p. 20).

La Sociedad de Naciones es una organización internacional creada por el Tratado de Versalles en 1919, con la premisa principal de asegurar la paz en el mundo. También se encarga de supervisar las comisiones creadas para tratar las cuestiones internacionales pertinentes.

Aunque el Pacto de la Sociedad de las Naciones de 1920 (LIGA DAS NAÇÕES, 1920) no mencionaba expresamente la protección de los refugiados, la realidad vivida por los países europeos en aquel momento, especialmente en lo que se refiere a los desplazamientos masivos debidos a las persecuciones sufridas a causa del final de la Primera Guerra Mundial, suscitó preocupación en la comunidad internacional, que, a través de la Sociedad de las Naciones, creó la Comisión para los Refugiados, que se ocuparía de las cuestiones específicas de estas personas, en particular a través del Comité de Refugiados, encabezado por el Sr. Fridtjof Nansen, primer Alto Comisionado de la Sociedad de las Naciones para los refugiados.

La protección otorgada a los refugiados en este período era de naturaleza legal y no humanitaria y el refugio se consideraba algo transitorio, que surgió naturalmente con el fin de la Primera Guerra Mundial, pero se hizo cada vez más común, mientras que "[...] los grupos de personas que buscaban protección crecían y la preocupación por sus destinos comenzaba a ser objeto de debate en la Sociedad de las Naciones" (ANDRADE, 1996, p. 23).

En este escenario, se destaca la importancia de la Sociedad de las Naciones en el contexto histórico de la protección jurídica de los refugiados, porque fue a partir de las preocupaciones y acciones de esta organización internacional que surgió en el derecho internacional la preocupación y la necesidad urgente de proteger a estas minorías. 
Sin embargo, debido a la aparición de nuevos conflictos, especialmente con el estallido de la Segunda Guerra Mundial, la Liga de las Naciones se disolvió y para asumir sus funciones, se creó en 1945 la Organización de las Naciones Unidas (ONU). Ya en su primer período de sesiones, se presentó a la Asamblea General la preocupación y la necesidad de crear un nuevo órgano dedicado exclusivamente a la cuestión de los refugiados.

Así, incluso antes de la aprobación de la Declaración Universal de los Derechos Humanos, el 15 de diciembre de 1946, la Asamblea General de la ONU aprobó la creación de la Organización Internacional para los Refugiados (OIR), con carácter provisional:

[...] identificar a los refugiados, expedir su documentación, darle asistencia a sus necesidades, atender los pedidos de repatriación, auxiliar en su integración local, y cuando sea necesario, intervenir para obtener su resarcimiento en un tercer país. ${ }^{1}$ (SANTIAGO, 2010, p. 86).

Sin embargo, incluso antes de que finalizara el mandato de la OIR, la Asamblea General de las Naciones Unidas ya estaba debatiendo quién asumiría su sucesión, mientras que, para hacer frente con eficacia a las dificultades derivadas del creciente número de refugiados a nivel mundial, era necesario adoptar criterios universalmente aceptados.

Y es por esta preocupación que la Declaración Universal de los Derechos Humanos del 10 de diciembre de 1948 (ONU, 1948) proclama en su artículo 14 que "[...] toda persona, víctima de persecución, tiene derecho a buscar y disfrutar del asilo en otros países". Un año después, el 3 de diciembre de 1949, la Asamblea General de la ONU creó el Alto Comisionado de las Naciones Unidas para los Refugiados (Acnur), otorgándole a esta organización la función exclusiva de brindar protección y protección a estas personas.

Acnur, al comienzo de su actuación, traía una concepción innovadora sobre el refugio, dándole a este instituto un carácter humanitario y apolítico. Dentro de este espíritu y buscando comprenderlo a fondo, se solicitó a un profesor del "Centre d'Etudes de Politique Etrangere" de París, el profesor Jacques Vernant, que hiciese un estudio sobre la temática de los refugiados. En él, se señaló lo siguiente:

[...] los problemas de los refugiados de un modo general, no limitándose a aquellos que se encuentran sobre la protección de ACNUR, son problemas profundos, lo que conlleva a que la crisis de los refugiados tiene como mal mayor, el carácter repetitivo y permanente ${ }^{2}$ (SANTIAGO, 2010, p. 88).

Ante este estudio exhaustivo, quedó evidenciada la necesidad de brindarle al instituto del refugio de una mayor atención, especialmente, en razón de la realidad que se vivenciaba en esa época. Fue entonces cuando la Asamblea General de la ONU el 26 de julio de 1951, aprobó la Convención Relativa al Estatuto de los Refugiados, considerada por la ONU como la Carta Magna de este instituto jurídico.

\footnotetext{
${ }^{1}$ Traducción hecha por los autores.

${ }^{2}$ Traducción hecha por los autores
} 


\section{Humanos}

Democracia

\subsection{Estatuto de los Refugiados de 1951 y su Protocolo de 1967}

La Convención de 1951 (ONU, 1951), también conocida como la Convención de 1951 sobre el Estatuto de los Refugiados, el Estatuto de los Refugiados y la Convención de Ginebra de 1951, fue discutida y desarrollada durante una conferencia de plenipotenciarios en Ginebra en julio de 1951.

Dado que esta conferencia tuvo lugar fuera de la estructura de la ONU, otros países que no formaban parte de esta organización, pero que estaban interesados en este tema, pudieron participar en la redacción del texto de la Convención de 51, que utilizó el propio estatuto de Acnur como referencia inicial, a pesar de que su redacción se finalizó en julio de 1951, sólo entró en vigor en 1954 (ANDRADE, 2010, p. 776).

Mientras se discutían las cuestiones que debía abarcar la Convención, se produjeron desacuerdos entre los países participantes. En primer lugar, en relación con la competencia ratione temporis de la Convención de 51, dado que algunos países sostienen que la definición de refugiado debe ser amplia, sin límite temporal alguno; otros pretenden que se establezca un límite temporal para el reconocimiento de un refugiado, y al final el texto normativo adopta el límite temporal, bajo la justificación de que, por lo tanto, es posible que los Estados midan el alcance de sus obligaciones.

Otra divergencia se produjo en relación con el límite geográfico, dado que, por una parte, algunos Estados tenían la intención de que la Convención de 51 se aplicara a cualquier refugiado en el mundo y, por otra, los Estados entendían que este instrumento debía aplicarse únicamente a los refugiados europeos, que necesitaban más protección, una posición ganadora y su incorporación en el texto de la Convención. Por lo tanto, al final de la Conferencia de Plenipotenciarios, el texto completo de la Convención de 51 se deriva de ella, que presenta en su primer artículo, el concepto de refugiado.

Conforme se establece en el artículo primero de la Convención de 1951, se considera refugiado a todo el que:

[...] como resultado de acontecimientos ocurridos antes del 1. 0 de enero de 1951 y debido a fundados temores de ser perseguida por motivos de raza, religión, nacionalidad, pertenencia a determinado grupo social u opiniones políticas, se encuentre fuera del país de su nacionalidad y no pueda o, a causa de dichos temores, no quiera acogerse a la protección de tal país; o que, careciendo de nacionalidad y hallándose, a consecuencia de tales acontecimientos, fuera del país donde antes tuviera su residencia habitual, no pueda o, a causa de dichos temores, no quiera regresar a él (ONU, 1951).

Ante este concepto que ofrece la Convención de 1951, se verifica que este instrumento

[...] estableció una limitación temporal y geográfica, una vez que la condición de refugiado se restringía a los acontecimientos ocurridos antes del 10 de enero de 1951 en el continente europeo. Eso significa que los refugiados solamente eran así reconocidos su lo fuesen en antes del 10 de enero de 1951. Si bien, se aplicó a miles de personas, pues hasta la década de los años 50 la mayoría de los refugiados eran europeos. Tal definición se mostró inoperante con el paso del tiempo (PIOVESAN, 2003, p. 119). 
Sin embargo, el desplazamiento masivo no se limitó a los europeos, mientras que en muchos otros países del mundo este fenómeno se repitió, quizás con la misma intensidad, y las personas que se vieron obligadas a abandonar sus países por las mismas razones declinaron en el artículo 1 de la Convención de 51, quedaron necesitadas de protección, simplemente porque no estaban, debido a limitaciones territoriales y temporales, cubiertas por el Estatuto de los Refugiados.

Ante esta situación, la comunidad internacional se dio cuenta de la necesidad de llenar este vacío, ampliando el alcance de la definición de refugiado, hecho por el cual se editó el Protocolo sobre el Estatuto de los Refugiados (ONU, 1967) el 31 de enero de 1967, que en su artículo 1 hace uso de las delimitaciones territoriales y temporales que existían hasta entonces.

Desde la elaboración del Protocolo de 67, de acuerdo con lo dispuesto en su artículo 10, $\S 20$, pasaron a considerarse como refugiados no sólo los europeos afectados por los acontecimientos ocurridos antes del 1 de enero de 1951, si no también cualquier persona del mundo que, en razón de un temor fundado de persecución por motivos de raza, religión, nacionalidad, grupo social u opiniones políticas, se encontrase fuera del país de su nacionalidad, y que no pudiese $o$, en base a ese temor, no quisiese valerse de la protección de ese país; o que, por no tener nacionalidad y estar fuera del país en donde tenía su residencia habitual, no podría o no quisiera regresar a él en razón de esos acontecimientos o por causa de esos temores (ONU, 1967).

En principio, para que un individuo tenga la consideración de refugiado es necesario que se den dos requisitos, los cuales son interdependientes: extraterritorialidad y fundado temor de persecución por motivos de raza, religión, nacionalidad, grupo social u opiniones políticas.

Nótese que el refugiado no es un extranjero común, por así decirlo, se trata de un extranjero que corre un riesgo dentro de su propio país (FOSTER; HATHAWAY, 2014, p. 17) y por lo tanto se ve obligado a salir de él.

Como se puede ver, la Convención del 51 y el Protocolo del 67, a pesar de regular la misma materia, son documentos independientes y distintos, siendo este último, como se ha visto, creado para eliminar del texto original el límite temporal y territorial previamente establecido, extendiendo al mismo tiempo el concepto de refugiado a los no europeos, y hay que señalar que es perfectamente posible que los Estados se adhieran a uno solo de ellos, lo que no les obliga frente a los otros no ratificados, ya que también se les permite adherirse a los dos.

Cabe señalar que la Convención de 51 y el Protocolo de 67 son instrumentos de protección global que ocupan la cima de la pirámide del instituto jurídico del refugio, mientras que el contenido de sus textos se utilizó como parámetro para la concepción de otros documentos posteriores que regulan el refugio tanto a nivel regional, como la Convención de la Organización de la Unidad Africana de 1969 y la Declaración de Cartagena sobre los Refugiados de 1984, como a nivel interno de los Estados, a ejemplo de la ley brasileña 9.474/97.

Según datos de Acnur, 145 Estados son signatarios de la Convención de 51, 146 Estados son signatarios del Protocolo de 67, 142 Estados son signatarios de ambos documentos y el número de signatarios de uno u otro documento es de 148 Estados. 
Por último, todos los países de la Unión Europea son signatarios del Convenio de 51 y del Protocolo de 67 y los Estados Unidos sólo son signatarios de este último documento, al que se adhirieron el 1 de noviembre de 1968.

\subsection{Mecanismos adoptados por la Unión Europea y los Estados Unidos para evitar la entrada de los refugiados en sus territorios}

En este tópico se presentarán dos casos en los que los Estados, a través de sus representantes, firmaron acuerdos y decretos ejecutivos destinados a limitar o incluso impedir la entrada de refugiados en sus territorios.

Como ha sido ampliamente difundido a través de todos los medios de comunicación, especialmente en 2015, hubo un flujo migratorio sin precedentes en Europa, sobre todo de personas que salieron de Siria debido a la guerra civil que sigue asolando ese país en la actualidad, en busca de protección en los países vecinos, especialmente Turquía, Líbano y Jordania.

Sin embargo, debido a la gran demanda de estos países en razón de la logística territorial, éstos pasaron por no admitir a más refugiados, los cuales se vieron obligados a buscar protección en los países europeos, cruzando la ruta de los Balcanes (ruta terrestre), así como cruzando el Mar Mediterráneo, siendo que Turquía era una de las principales puertas de entrada a Europa.

Hay que decir que la gran mayoría de estas personas entraron en los países europeos de forma irregular, especialmente debido a la urgencia de salir de su país, y ni siquiera fue posible proporcionar la documentación necesaria para su debida entrada.

En este contexto, y con el fin de resolver el problema de la migración irregular y el flujo masivo de refugiados que se desplazan a los países europeos, se firmó un acuerdo entre la Unión Europea y Turquía, denominado Declaración UE-Turquía (CONSELHO EUROPEU, 2016), publicada por el Consejo de la Unión Europea el 18 de marzo de 2016.

La parte del acuerdo que importa para este trabajo es el punto en el que se acordó que "[...] todos los nuevos migrantes irregulares que lleguen a las islas griegas desde Turquía a partir del 20 de marzo de 2016 serán devueltos a este último país" (CONSELHO EUROPEU, 2016).

Además de este acuerdo, otros mecanismos diferentes han sido adoptados por los países europeos, por lo que puede llamarse una "política internacional de cierre de fronteras", a través de la creación de barreras físicas, como la construcción de muros fronterizos por parte de los gobiernos de Bulgaria y Hungría.

En el mismo sentido, se han creado barreras jurídicas en relación con la cuestión de las leyes nacionales, los decretos y los acuerdos restrictivos para los refugiados, todo ello con el objetivo de impedir su entrada en el territorio europeo o incluso con el objetivo de convertirse en un destino menos atractivo para los refugiados, por así decirlo, siguiendo el ejemplo de una ley aprobada por Dinamarca, que permite la confiscación de los bienes de los refugiados que no se consideran esenciales, un procedimiento que se reproduce en Suiza y Alemania. 
Además de la adopción de esta postura en Europa, de manera similar, los EE.UU. también han estado cerrando sus fronteras, mientras que recientemente fueron firmadas por el Presidente Donald J. Trump, los Decretos Ejecutivos número 13.769, del 27 de enero de 2017 (EUA, 2017f) y 13.780, del 6 de marzo de 2017 EUA., 2017a), llamados documentos "Protecting the Nation from Foreign Terrorist Entry In to the United States".

El contenido de estos decretos de mayor interés para este trabajo es la suspensión del programa de admisión de refugiados (Refugee Admissions Program - Usrap) en los EE.UU., por un período indefinido para aquellos refugiados nacidos en Siria -sólo en el decreto $13.769^{3}$ y por un período de 120 días para los demás refugiados, siendo que después de este período, el programa se reanudaría y se restringiría a los ciudadanos de países para los cuales el Secretario de Estado, el Secretario de Seguridad Nacional y el Director de Inteligencia Nacional, juntos, determinasen que no pondría en peligro la seguridad y el bienestar de la población de los EE.UU.

\footnotetext{
${ }^{3}$ Sección 5: Reajuste del Programa de Admisión de Refugiados de los Estados Unidos para el año fiscal 2017.

(a) El Secretario de Estado suspenderá el Programa de Admisión de Refugiados de los Estados Unidos (Usrap) por 120 días. Durante este período de 120 días, el Secretario de Estado, junto con el Secretario de Seguridad Nacional y en consulta con el Director de Inteligencia Nacional, revisará la solicitud del Usrap y el proceso de adjudicación para determinar qué procedimientos adicionales deben adoptarse con el fin de garantizar que los aprobados para la admisión de refugiados no representen una amenaza para la seguridad y el bienestar de los Estados Unidos y aplicará estos procedimientos adicionales. Los solicitantes del programa de refugiados que ya están pasando por el proceso del Usrap pueden ser admitidos después de la iniciación y finalización de estos procedimientos revisados. En la fecha que complete el período de 120 días después de la fecha de este decreto, la Secretaría de Estado reanudará las admisiones del USRAP sólo para los nacionales de países para los cuales la Secretaría de Estado, la Secretaría de Seguridad Nacional y el Director de Inteligencia Nacional determinen conjuntamente que dichos procedimientos adicionales son suficientes para garantizar la seguridad y el bienestar de los Estados Unidos.

b) Al reanudar las admisiones en el Usrap, el Secretario de Estado, en consulta con el Secretario de Seguridad Nacional, tiene instrucciones de introducir otros cambios, en la medida en que lo permita la ley, para dar prioridad a las solicitudes de asilo presentadas sobre la base de la persecución religiosa, siempre que la religión de la persona sea una religión minoritaria en su país de origen. Cuando sea necesario y apropiado, los Secretarios de Estado y de Seguridad Nacional recomendarán al Presidente la legislación que pueda ayudar en esta priorización.

c) De conformidad con la sección 212(f), título 8, del Código de los Estados Unidos, 1182(f), declaro por la presente que la entrada de personas nacidas en Siria como refugiados es perjudicial para los intereses de los Estados Unidos, y por la presente suspendo dicha entrada hasta que determine que el Usrap ha sido debidamente modificado para garantizar que la admisión de refugiados sirios sea conforme con el interés nacional.

(d) De conformidad con la Sección 212(f) del Título 8 del Código de los Estados Unidos, 1182(f), por la presente declaro que la entrada de más de 50,000 refugiados en el año fiscal 2017 sería perjudicial para los intereses de los Estados Unidos, por lo tanto, suspendo dicha entrada hasta que determine que otras admisiones serían de interés nacional.

e) Sin perjuicio de la suspensión temporal impuesta en virtud del apartado a) del presente artículo, los Secretarios de Estado y de Seguridad Interior podrán decidir conjuntamente, caso por caso, admitir a personas en los Estados Unidos como refugiados a su discreción, pero sólo si determinan que la admisión de esas personas como refugiados redunda en interés nacional, incluso cuando la persona pertenezca a una minoría religiosa en su país de origen y sea objeto de persecución religiosa; cuando la admisión de esa persona permita a los Estados Unidos adaptar su conducta a un acuerdo internacional preexistente; o cuando la persona ya esté en tránsito y niegue su admisión causaría dificultades indebidas - y no plantea ningún riesgo para la seguridad o el bienestar de los Estados Unidos.

(f) El Secretario de Estado, dentro de los 100 días siguientes a la fecha de este decreto, presentará al presidente un informe inicial sobre el progreso de la directiva contenida en la subsección (b) de esta sección con respecto a la priorización de las reclamaciones hechas por individuos basadas en la persecución religiosa y presentará un segundo informe dentro de los 200 días siguientes a la fecha de este decreto.

(g) Es política del Poder Ejecutivo, en la medida en que lo permita la ley y sea factible, que las jurisdicciones estatales y locales tengan un papel en la determinación de la colocación o asentamiento en sus jurisdicciones de los extranjeros que califiquen para ser admitidos en los Estados Unidos como refugiados. Con este fin, el Secretario de Seguridad Nacional examinará la ley vigente para determinar en qué medida, en virtud de la ley aplicable, las jurisdicciones estatales y locales pueden tener una mayor participación en el proceso de determinación de la colocación o reasentamiento de refugiados en sus jurisdicciones y formulará una propuesta para promover dicha participación legalmente.
} 
Ambos decretos fueron objeto de numerosas acciones en los Tribunales Federales de los Estados Unidos, las cuales fueron propuestas por varios Estados, en busca de una declaración de inconstitucionalidad de los mencionados decretos ejecutivos y, en consecuencia, su ejecución se vio obstaculizada. Así, este artículo abordará dos acciones propuestas ante los Tribunales Federales de Estados Unidos, las cuales cuestionaron la legalidad de ambos decretos.

Tan pronto como el Decreto no. 13.769 entró en vigor en enero de 2017, los Estados de Washington y Minnesota presentaron una demanda ante el Tribunal Federal de Washington, en Seattle, el 30 de enero de 2017 (EUA, 2017d), solicitando una orden de restricción temporal que solicitaba la suspensión de dicha orden ejecutiva, principalmente debido a su aparente inconstitucionalidad, la cual fue debidamente reconocida por el juez federal James Robart.

La decisión antes mencionada fue confirmada por el Noveno Circuito de la Corte de Apelaciones de los Estados Unidos, debido a una apelación presentada por el Presidente Donald J. Trump, Caso n. 17-35105, manteniendo la suspensión del decreto (EUA, 2017e). Después de la decisión del Tribunal de Apelación, no se presentaron otras apelaciones, por lo que el caso se cerró el 17 de marzo de 2017.

En vista de ello, se redactó un nuevo decreto, como se mencionó anteriormente, con el número 13.780, que contenía algunos cambios en relación con el anterior, e incluso antes de su entrada en vigor, ya había sido objeto de nuevas demandas, que también ponían en tela de juicio su inconstitucionalidad.

El Estado de Hawái fue el primero en presentar una orden de restricción temporal a nivel nacional, solicitando la suspensión del nuevo decreto, CV.NO.17-00050 DKW-KSC (EUA, 2017b), que fue otorgado por el Juez Federal de Honolulu Derrick K. Watson, el 15 de marzo de 2017, un día antes de su entrada en vigor. Nuevamente, el Presidente Donald J. Trump apeló esta decisión ante la Corte de Apelaciones de los Estados Unidos, Caso no. 17-15589 (EUA., 2017c), y el 26 de junio de 2017 esta apelación fue parcialmente concedida por la corte, razón por la cual el Programa de Admisión de Refugiados en los EE.UU., está suspendido por 120 días, pudiendo ser apelada esta decisión.

Cabe destacar que, a priori, en ambos casos, los decretos fueron suspendidos preliminarmente, según el entendimiento de los jueces, primero por su patente ilegalidad, inconstitucionalidad, estigmatizando al mismo tiempo a inmigrantes, refugiados y musulmanes, y segundo porque los argumentos planteados por el Presidente Donald J. Trump no fueron suficientes para demostrar la necesidad de emitir el documento, dado que no había evidencia de los graves riesgos inminentes para la seguridad de los Estados Unidos.

\subsection{Mecanismos adoptados por la Unión Europea y Estados Unidos contra el Instituto Legal de la Responsabilidad Internacional del Estado}

Presentados los casos anteriores, que contemplan una política de cierre de fronteras, capaz de obstaculizar e incluso impedir la entrada de solicitantes de asilo en determinados países, es necesario discutir brevemente la Responsabilidad Internacional del Estado, con el fin de analizar este contexto en relación con el panorama general del refugio que también se presenta en el cuerpo de este trabajo. Sobre el tema: 
Assim como os atos ilícitos praticados pelos cidadãos, no âmbito do Direito interno dos Estados, merecem uma devida reprimenda, a prática de um ato ilícito internacional, entendido este como todo ato violador de uma norma de DIP, por parte de um Estado em relação aos direitos de outro, gera igualmente a responsabilização do causador do dano, em relação àquele Estado contra o qual o ato ilícito foi cometido (MAZZUOLI, 2016, p. 615).

En este sentido, para que la Responsabilidad Internacional del Estado quede configurada, es necesaria la presencia de ciertos elementos esenciales, a saber, la práctica de un acto ilícito, como el que atenta contra una norma de derechos del pueblo: un principio general, una norma consuetudinaria, una disposición de un tratado en vigor, entre otras especies; la imputabilidad, es decir, la acción u omisión calificada de ilícita, debe imputarse a un Estado o a una organización internacional y, como último elemento, la existencia de un daño, que se convierte en indispensable para caracterizar la responsabilidad internacional del Estado (REZEK, 2000, p. 262).

Cabe mencionar que la responsabilidad internacional es prácticamente desconocida para la responsabilidad penal, que sólo tiene lugar en el derecho internacional, excepcionalmente, en casos de genocidio, crímenes de guerra y crímenes de lesa humanidad, lo que dará lugar a la responsabilidad personal de la persona ante la Corte Penal Internacional (MAZZUOLI, 2016, p. 617-618).

Analizando el acuerdo firmado entre la Unión Europea y Turquía, a la luz del instituto legal de Responsabilidad Internacional del Estado, es evidente que los países europeos, al devolver a Turquía los migrantes que ingresan irregularmente a sus países, están practicando un acto ilícito internacional, mientras que como países signatarios de la Convención de 51 y el Protocolo de 67, se les prohibiría retornar a cualquier persona que entre en sus territorios con estatus de refugiado, en honor al principio de jus cogens del non-refoulement.

En este sentido, aunque la persona que se encuentra en situación de refugio entre irregularmente en un país en el que busca protección, no puede ser devuelta, bajo pena de que el país que la devolvió sea considerado internacionalmente responsable del delito cometido, he aquí todos los elementos esenciales para la caracterización de la responsabilidad internacional del Estado, en particular, el hecho ilícito, la imputabilidad y el daño.

Esta peculiaridad del acuerdo sigue siendo contradictoria, especialmente porque la Unión Europea ha estado impidiendo la entrada de Turquía en el bloque económico debido a la historia de violaciones de los derechos humanos por parte del Estado turco (PARLAMENTO EUROPEO, 2016), y es algo inocuo creer que Turquía funcionaría como un tercer país seguro, capaz de recibir a los refugiados de manera efectiva.

Asimismo, el decreto ejecutivo emitido por el actual Presidente de los Estados Unidos, Donald J. Trump, que suspendió el Programa de Admisión de Refugiados en este país por un período de 120 días a partir del 26 de junio de 2017, atenta contra los compromisos asumidos por él en el ámbito internacional, mientras que como signatario del Protocolo de 67 tendría el deber de recibir en su territorio a todas y cada una de las personas que buscan refugio. 
De ello se deduce que, si bien el presidente de los Estados Unidos ha obtenido un éxito parcial en su petición, logrando la suspensión de este programa, no hay duda de que está incurriendo en la práctica de un acto ilícito, debido al incumplimiento de un compromiso asumido a través de su adhesión a un tratado.

Cabe señalar que esta postura adoptada recientemente por el Presidente de los Estados Unidos, incluso contradice su carta magna, ya que el principio más importante del sistema constitucional de los Estados Unidos es la equidad, es decir, el derecho de los ciudadanos a la igualdad de consideración y el respeto de la ley (APPIO, 2008, p. 198), un principio que se viola explícitamente en los decretos ejecutivos citados anteriormente. Sobre el tema:

Neste contexto, o direito internacional dos refugiados passa a lidar com problemas novos, que fogem do padrão até então comum de mera análise da subsunção dos casos concretos aos requisitos previstos na Convenção de 1951, ao mesmo tempo em que a vontade política dos Estados em receber novos refugiados diminui. Da conjunção de tais fatores, resultam diversas políticas públicas que têm como objetivo principal a repulsão de migrantes e a proteção das fronteiras, violando as obrigações contraídas internacionalmente (SANTIAGO, 2010, p. 78).

Por lo tanto, aunque los países mencionados son signatarios de la Convención de 51 y del Protocolo de 67, las violaciones de los compromisos internacionales relativos a la protección de los refugiados siguen siendo evidentes y una posible vía para una futura reparación.

Cabe recordar que, en un caso similar, Bolivia siguió siendo signataria de la Convención del 51 y su Protocolo del 67, condenada por la Corte Interamericana de Derechos Humanos el 13 de febrero de 2013 (CIDH, 2015), por la expulsión de la familia Pacheco Tineo a su país de origen, Perú.

Los miembros de esta familia fueron devueltos sumariamente y sin ninguna razón justa al país donde sus vidas estaban en peligro, en total contradicción con el principio establecido considerado como una norma de jus cogens de non-refoulement, inscrito en el Artículo 33 de la Convención de 1951.

Lo que se observa es que ante las evidentes violaciones de la Convención de 1951 y su Protocolo de 1967, el poder judicial se ha esforzado por hacer cumplir los compromisos internacionales asumidos por los Estados, como forma de proteger los derechos y garantías de los refugiados.

\section{CONCLUSIÓN}

En el desarrollo de este trabajo se observó que el Instituto del Refugio ha progresado en general desde su creación. Sin embargo, no se puede negar que ha habido algunos reveses que parecen venir del creciente número de solicitantes de asilo y refugiados en todo el mundo en los últimos años. Frente al caos del desplazamiento forzado masivo, y como se ha visto, los Estados han comenzado a crear mecanismos para impedir que estas personas entren en sus fronteras en una forma clara de eludir los compromisos asumidos internacionalmente. 
Se observa, por tanto, que la mayoría de los países que son signatarios de la Convención de 51 sólo para cumplir con los protocolos, se limitan de manera muy superficial a ofrecer el "suelo" de su país a los que son reconocidos como refugiados; sin embargo, no establece una condición mínima para una estancia digna, ni pretende garantizar los derechos que les son concedidos por los instrumentos globales de protección.

Parece que abrir las puertas de un país para recibir a los refugiados se ha considerado un problema para los Estados, que, de forma individualista y sobre todo ilegítima, buscan subterfugios para mantenerlos alejados de sus fronteras.

Es lamentable que los Estados opten por invertir miles de millones en la creación de muros fronterizos, o incluso por gastar valores exorbitantes con otros Estados, con el fin de legitimarlos como receptores perfectos de refugiados, como una forma de exportar a estos países, individuos que serían su responsabilidad, por así decirlo.

$\mathrm{Si}$, por otro lado, todo el dinero gastado en esta sórdida política de "cierre de fronteras" se convirtiera en favor de una admisión digna de los refugiados, es cierto que la crisis instalada en todo el mundo no habría alcanzado proporciones elevadas.

Sin embargo, la realidad que se presenta ante todos los acontecimientos que rodean la cuestión hoy gira en torno a la conveniencia y no a un contexto humanitario, mientras que, si es oportuno que el Estado reciba refugiados en su territorio, lo hará. De lo contrario, cerrará sus puertas, todo en su forma libre, y está claro que las cuestiones económicas siempre se solaparán con las demás.

Frente a esta situación, el instituto de refugio parece estar comenzando a desprenderse de su carácter exclusivamente administrativo, empezando a caminar de manera incipiente hacia su judicialización, lo cual se ha demostrado en este trabajo; mientras que los temas relacionados con este tema han llegado a los tribunales de diferentes maneras.

Por lo tanto, se recuerda que el individuo, que se ve obligado a huir de su país por razones ajenas a su voluntad, deja atrás no sólo su patria, sino todo lo que le pertenece, especialmente su familia, su patrimonio, su cultura, en definitiva, toda una historia; es como si tuvieran que enterrar una vida para iniciar otra, y lo único que les queda es la esperanza.

Precisamente por estas importantes razones es necesario que se les conceda el mínimo de protección y una acogida digna, especialmente por parte de los Estados, que tienen esta obligación legal.

Ante este contexto, es necesario pensar que es posible que cualquier pueblo, de todas las naciones, pueda algún día ocupar la condición de refugiado, sobre todo en un mundo en constante transformación, y que así abrazaríamos el refugio en su concepto genuino, especialmente con un espíritu humanitario, sin permitir que ningún otro interés, especialmente el económico, prevalezca sobre la dignidad humana de estas minorías, que también son vulnerables.

\section{REFERENCIAS}

ACNUR. Alto Comisionado de las Naciones Unidas para los Refugiados. Global Trends: Forced Displacement in 2015. Disponible en: http://www.unhcr.org/576408cd7.pdf. Acceso en: 25 abr. 2017.

ANDRADE, J. H. F. de. Direito internacional dos refugiados: evolução histórica. Rio de Janeiro: Renovar, 1996. 
ANDRADE, J. H. F. de. Guerra fria e refugiados: da gênese política do Acnur e da Convenção de 1951. In: IKAWA, Daniela; PIOVESAN, Flávia; SARMENTO, Daniel. Igualdade, diferença e direitos humanos. Rio de Janeiro: Editora Lumen Juris, 2010.

APPIO, E. Direito das minorias. São Paulo: Revista dos Tribunais, 2008.

$\mathrm{CIDH}$. Comissão Interamericana de Direitos Humanos. Caso Familia Pacheco Tineo Vs. Estado Plurinacional de Bolívia: Supervisão de Cumprimento de Sentença de 17/4/2015. Disponible en: http://www.corteidh.or.cr/docs/ supervisiones/pachecotineo_17_04_15.pdf. Acceso en: 27 abr. 2017.

CONSELHO EUROPEU. Declaração UE-Turquia, 18 de março de 2016. Disponível em: http://www.consilium.europa.eu/pt/press/press-releases/2016/03/18-eu-turkey-statement/__Acesso em: 6 mar. 2017.

EUA. Executive Order 13.780, de 6 de março de 2017. 2017a. Disponible en: https://www.whitehouse.gov/the-press-office/2017/03/06/executive-order-protecting-nation-foreign-terrorist-entry-united-states. Acceso en: 17 mar. 2017.

EUA. Hawai'i and Ismail Elshikh v. Trump et al. (CV. NO. 17-00050 DKW-KSC) ORDER GRANTING MOTION TO CONVERT TEMPORARY RESTRAINING ORDER TO A PRELIMINARY INJUNCTION, Filed March, 29, 2017. $2017 \mathrm{~b}$. Disponible en: https://www.buffalo.edu/content/dam/www/immigration-update/AILA\%20-\%20Hawaii\%20 v.\%20Trump,\%20CV\%2017-00050\%20DKW-KSC\%20-\%20Order\%20Granting\%20Motion\%20to\%20Convert\%20 TRP\%20to\%20Preliminary\%20Injunction\%20170329.pdf. Acceso en: 20 abr. 2017.

EUA. Hawai'i and Ismail Elshikh v. Trump et al. (No. 17-15589), Filed April, 28, 2017. 2017c. Disponible en: http:// cdn.ca9.uscourts.gov/datastore/general/2017/04/29/17-15889\%20Reply\%20brief.pdf. Acceso en: 15 mayo 2017.

EUA. Washington et al. v. Trump et al. (CASE NO. C17-0141JLR) TEMPORARY RESTRAINING ORDER, Filed March, 2, 2017. 2017d. Disponible en: http://cdn.ca9.uscourts.gov/datastore/general/2017/02/03/17-141_TRO_order. pdf. Acceso en: 17 mar. 2017.

EUA. Washington et al. v. Trump et al. (No. 17-35105; D.C. No. 2:17-cv-00141) Amended Order, Filed March 17, 2017. 2017e. Disponible en: http://cdn.ca9.uscourts.gov/datastore/opinions/2017/03/17/17-35105_Amd_Order.pdf. Acceso en: 30 mar. 2017.

EUA. Executive Order 13.769, de 27 de janeiro de 2017. 2017f. Disponible en: https://br.usembassy.gov/pt/ato-executivo-para-proteger-nacao-contra-entrada-de-terroristas-estrangeiros-no-eua/. Acceso en: 6 mar. 2017.

FOSTER, M.; HATHAWAY, J. The law of refugee status. 2. ed. Reino Unido: Cambridge University Press, 2014.

FRANCO FILHO, G. de S. Refúgios e refugiados climáticos. In: Revista Brasileira de Direitos Humanos. São Paulo: Lex Magister, 2013.LIGA DAS NAÇÕES. Pacto da Liga das Nações de 1920. Disponible en: http://pfdc.pgr.mpf. mp.br/atuacao-e-conteudos-de-apoio/legislacao/segurancapublica/PACTO_DA_SOCIEDADE_DAS_NACOES.pdf. Acceso en: 29 abr. 2017.

MAZZUOLI, V. de O. Curso de direito internacional público. 10. ed. São Paulo: Revista dos Tribunais, 2016.

ONU. Organização das Nações Unidas. Convenção relativas aos refugiados de 1951. Disponible en: http://www. acnur.org/t3/fileadmin/Documentos/portugues/BDL/Convencao_relativa_ao_Estatuto_dos_Refugiados.pdf. Acceso en: 17 abr. 2017.

ONU. Organização das Nações Unidas. Declaração Universal de Direitos Humanos de 10 de dezembro de 1948. Disponible en: http://www.ohchr.org/EN/UDHR/Documents/UDHR_Translations/por.pdf. Acceso en: 20 mar. 2017.

ONU. Organização das Nações Unidas. Protocolo de 1967 Relativo ao Estatuto dos Refugiados. Disponible en: http://www.acnur.org/t3/fileadmin/Documentos/portugues/BDL/Protocolo_de_1967_Relativo_ao_Estatuto_ dos_Refugiados.pdf. Acceso en: 17 abr. 2017.

PACÍFICO, A. M. C. P. O capital social dos refugiados: bagagem cultura e políticas públicas. Maceió: Edufal, 2010.

PARLAMENTO EUROPEU. Resolução do Parlamento Europeu sobre as relações UE-Turquia (2016/2993(RSP). Disponible en: http://www.europarl.europa.eu/sides/getDoc.do?pubRef=-//EP//TEXT+MOTION+P8-RC-2016-1276+0+DOC+XML+V0//PT. Acceso en: 17 abr. 2017.

PIOVESAN, F. Temas de direitos humanos. São Paulo: Max Limonad, 2003.

REZEK, J. F. Direito Internacional Público: curso elementar. 8. ed. São Paulo: Saraiva, 2000.

SANTIAGO, J. R. de. Derechos Humanos, Derecho de los Refugiados: evolución y convergencias. In: PEYTRIGNET, Gérard; SANTIAGO, Jaime Ruiz; O refúgio no direito internacional contemporâneo: entre a segurança nacional e a proteção do indivíduo. 2010. Dissertação (Mestrado) - Universidade do Estado do Rio de Janeiro, Rio de Janeiro, 2010. 